\title{
IDŐJÁRÁS
}

Quarterly Journal of the Hungarian Meteorological Service

Vol. 125, No. 1, January-March, 2021, pp. 83-104

\section{Spatial and temporal variability of precipitation extreme indices in arid and semi-arid regions of Iran for the last half-century}

\author{
Sadegh Karimi ${ }^{1}$, Hamid Nazaripour ${ }^{2, *}$, and Mohsen Hamidianpour ${ }^{2}$ \\ ${ }^{1}$ Department of Geography
}

Shahid Bahonar University of Kerman, Kerman, Iran.

${ }^{2}$ Department of Physical Geography

University of Sistan and Baluchestan, Zahedan, Iran.

*Corresponding authorE-mail: h.nazaripour@gep.usb.ac.ir;

(Manuscript received in final form April 15, 2020)

\begin{abstract}
Precipitation variability analysis, on different spatial and temporal scales, has been of great concern during the past century because of the attention given to global climate change by the scientific community. According to some recent studies, the Iranian territory has been experienced a precipitation variability, especially in the last 50 years, and the arid and semi-arid areas seem to be more affected. The present study aims to analyze precipitation extreme indices over a wide time interval and a wide area, detecting potential trends and assessing their significance. The investigation is based on a wide range of daily and multi-day precipitation statistics encompassing basic characteristics and heavy precipitation. Two different methods of trend analysis and statistical testing are applied, depending on the nature of the statistics. Linear regression is used for statistics with a continuous value range, and logistic regression is used for statistics with a discrete value range. The trends are calculated on annual and seasonal bases for the years 1951-2007. Statistical analysis of the database highlight that a clear trend signal is found with a high number of sites with a statistically significant trend. In winter, significant increases are found for all statistics related to precipitation strength and occurrence. In spring, statistically, significant increases are found only for the statistics related to heavy precipitation, whereas precipitation frequency and occurrence statistics show little systematic change. The trend signal is strongest in highlands and mountainous terrains. In autumn and summer, the heavy and basic precipitation statistics did not show statistically significant trends.
\end{abstract}

Key-words: trend analysis, regression, precipitation variability, precipitation extremes, APHRODITE 


\section{Introduction}

Extreme weather events (droughts, heavy rainfall, floods, and heatwaves) are a matter of great topical importance and interest in a variety of environmental and social situations. One of the anticipated effects of climate change is the possible increase in both the frequency and intensity of extreme weather events. Heavy precipitation events are among the most disruptive of atmospheric phenomena. Changes in extreme precipitation events have significant impacts and pose serious challenges to societies, especially in arid and semi-arid environments. Such extremes are likely to have profound impacts on human societies (e.g., Zhang et al., 2005) and can lead to loss of lives and property. Climate extremes, as defined by the World Meteorological Organization (WMO), are rare meteorological and climatological phenomena that surpass a defined threshold (Das et al., 2003).

Understanding the mechanisms associated with extreme events at the regional scale could provide useful insights for resource planners, system managers, and policymakers to help to mitigate financial losses; therefore, comprehensive regional studies are crucial to assess the mechanisms and impacts of extreme events in a global context (Soltani et al., 2016).

There are numerous regional studies of recent trends and variability in the precipitation nature over Iran (Alijani et al., 2008; Amiri and Eslamian, 2010; Ghahraman and Taghvaeian, 2010; Raziei et al., 2008; Abbaspour et al., 2009; Abolverdi et al., 2014, 2016; Modarres and Sarhadi, 2009; Hasaniha and Meghdadi, 2010; Tabari and Talaee, 2011a, 2011b; Tabari et al., 2012; Tabari and Aghajanloo, 2013; Terink et al., 2013; Nazaripour and Daneshvar, 2014; Zhang et al., 2011; Dhorde et al., 2014; Darand et al., 2015).

However, there has been little work on precipitation related extremes in Iran. Prior research has shown changes in the frequency and intensity of precipitation extremes over the past century in Iran (Alijani, 2007; Sabzevari et al., 2015; Rahimzadeh et al., 2009; Sohrabi et al., 2013; Tabatabai and Hosseini, 2003; Taghavi, 2010; Marofi et al., 2011; Dinpashoh et al., 2004; Zhang et al., 2011; Peterson, 2005; Molanejad et al., 2014; Tabari et al., 2014). The international reports emphasized the lack of information on trends and changeability in daily climate and climate extremes (Nicholls et al., 1996). Most of the studies in Iran were conducted based on monthly and yearly dataset.

Floods are the most significant natural consequences of extreme precipitations in arid and semi-arid regions. More than 80 percent of Iran's territory is located in the arid and semi-arid zone of the world. During the past 60 years (1951-2010), more than 4670 flood events have been recorded in Iran, 42 percent of them occurred in the last decade (Molanejad and Ranjbar, 2014). During recent decades, the arid and semi-arid regions of Iran have experienced several events of extreme precipitation conditions that have led to severe damages and fatalities. 
According to a global assessment report in disaster risk reduction (UN, 2009), in the period of 1986-2007, among the flood-addected Iranian provinces, Kerman was in the second rank in terms of death per 10,000 inhabitants. Moreover, the highest number of buildings damaged or destroyed was observed in Kerman. Also, according to the Iran Water Resources Management Company report (IWRMC, 2006), in the period of 1972-1996, in terms of flood occurrence, the study area was the third most affected area with 72 events. One of the most important events in the study area was the 1993 flood event. In this flood, 211 people have been killed. These events in recent decades have raised concern that the frequency of precipitation extremes has gradually changed over the 20th century, possibly in response to global climate change.

Although the science community unanimously agrees that any changes in frequency and intensity of extreme climate events would affect significantly the natural system and human society, little information on trends and variability in daily climate and climate extremes is available (Nicholls et al., 1996). Therefore, a study on extreme climate events at the watershed scale is necessary to provide useful insights for resource planners, system managers, and policymakers concerning the climate variability and the responsible operations and resource management.

This paper builds on the earlier findings for Iran by examining trends in indices for extremes of daily precipitation. Investigations of extreme events have not yet materialized for arid and semi-arid lands of Iran. In this study, we investigate long-term variations and trends of precipitation extremes during the last halfcentury in arid and semi-arid regions of Iran. For this purpose, daily precipitation data are analyzed from a dense network, all of which have been continuously operated since 1951. The trend analysis is based on a wide range of diagnostics, covering basic precipitation statistics and heavy precipitation events. In this study, we undertake a trend analysis for a range of diagnostics with different data characteristics. To account for the different nature of the diagnostics, we apply two different statistical methods for trend estimation and statistical testing: linear regression and a non-parametric trend test for diagnostics with continuous data (e.g., precipitation amounts) and logistic regression for discrete data (e.g., the number of events above a threshold).

\section{Data and methodology}

The data used in this study consisted of daily precipitation in one of the arid and semi-arid regions of Iran (see Fig. 1). This data are derived from the APHRODITE database, which has been launched in 2006 by the research foundation of Japan Meteorological Agency with the membership of several other countries. This database has been formed based on precipitation gauging stations of such sources as local meteorological and hydrological organizations, regional 
researchers, the Global Historical Climatology Network (GHCN), the Carbon Dioxide Information Analysis Center (CDIAC), the National Center for Atmospheric Research (NCAR-DS), the National Climate Data Center (NCDC), and the Global Telecommunication System (GTS) (Yatagai et al., 2012; Hamada et al., 2011). The APHRODITE database daily gridded precipitation data for the Middle East region have been prepared with $0.5 \times 0.5$ and $0.25 \times 0.25$ resolution for the time interval 1951 to 2007.

In this study, the version V1101 of APHRODITE database in the Middle East on the daily gridded precipitation data has been utilized for one of the arid and semi-arid regions of Iran with $0.25 \times 0.25$ degree of geographical longitude/latitude resolution. In this research, extraction of daily precipitation data for the study area has been conducted by using the INPOLYGON function in MATLAB 2015b software. Thus, a sub-database has been formed with a $P_{20819 * 268}$ structure. Study area and spatial coverage of daily precipitation network are shown in Fig. 1.

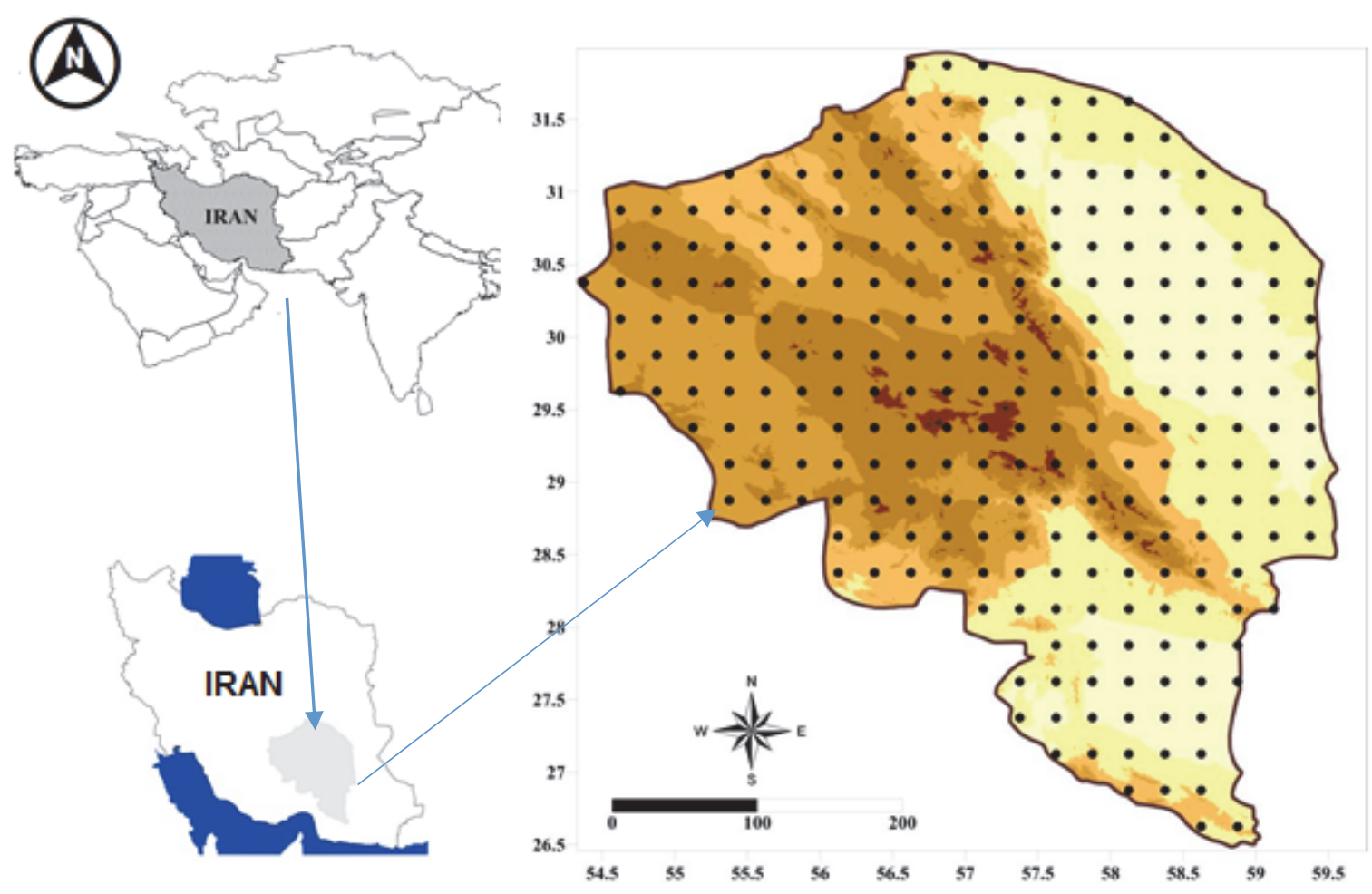

Fig. 1. Study area and database station location $(0.25 \times 0.25)$.

To cover long-term trends from a range of characteristics in precipitation extremes, we considered several diagnostics evaluated from time series of daily precipitation totals. Many of these diagnostics were found to be useful as a reference for comparing trend results between different regions (Nicholls and 
Murray, 1999). The diagnostics will be called indices in the remainder of the paper. The set of indices is listed in Table 1. They are grouped into two different categories: basic and heavy precipitation indices. Category 'basic' is not necessarily indicative of extremes, but the wet-day frequency, mean precipitation, and wet-day intensity are useful statistics for interpretation. A threshold of $1 \mathrm{~mm}$ is chosen for wet days. Category 'heavy precipitation' encompasses several indices defined in terms of threshold exceedances. These indices arethe following ones: heavy precipitation threshold ( $\mathrm{pqN})$, heavy precipitation days ( $\mathrm{pnlN})$, heavy precipitation proportion $(\mathrm{pflN})$, greatest $\mathrm{N}$-day precipitation $(\mathrm{pxNd})$, heavy precipitation frequency ( $\mathrm{pnNmm})$, precipitation day frequency ( $\mathrm{wd}$ ), mean precipitation (pav) and precipitation intensity (pint), respectively based in Table 1. All indices are calculated individually based on STARDEX (Climate Research Unit, 2005) for the whole network, resulted in annual and seasonal time series for 1951-2007.

Table 1. List of extreme precipitation indices used in this study. The indices are grouped into two categories (from top to bottom). The last column indicates the method used to estimate the trend: linear regression (linear), logistic regression using event counts (logit.counts), and logistic regression using event probabilities (logit.probs) [8].

\begin{tabular}{|c|c|c|c|c|}
\hline No. & $\begin{array}{c}\text { Name } \\
\text { (ID) }\end{array}$ & Description & Trend & Unit \\
\hline 1 & $\mathrm{pqN}$ & NNth percentile of wet-day amounts $(\mathrm{NN}=90,95)$ & Linear & $\mathrm{mm} /$ day \\
\hline 2 & pnlN & $\begin{array}{l}\text { Number of events }>\text { long-term NNth percentile }(\mathrm{NN}= \\
85,90)\end{array}$ & Logit.counts & day \\
\hline 3 & pflN & $\begin{array}{l}\text { The fraction of total precipitation above long-term 90th } \\
\text { percentile }\end{array}$ & Linear & $\%$ \\
\hline 4 & $\mathrm{pxNd}$ & Maximum $\mathrm{N}$-day total precipitation $(\mathrm{N}=3,4,5)$ & Linear & $\mathrm{mm}$ \\
\hline 5 & pnNmm & Number of events $\geq 5 \mathrm{~mm}$ & Logit.counts & days \\
\hline 6 & wd & Frequency of wet days (precipitation $\geq 1 \mathrm{~mm}$ ) & Logit.probs & days \\
\hline 7 & pav & Precipitation average & Linear & $\mathrm{mm} /$ day \\
\hline 8 & pint & Simple daily intensity (rain per rain day) & Linear & rain/wet-day \\
\hline
\end{tabular}

Two different methods were used to calculate trend magnitudes and to test for statistical significance, depending on the value range of the index. For indices with a continuous value range (e.g., mean precipitation and precipitation 
intensity), trends were calculated with conventional linear regression. These indices are indicated by 'linear' in Table 1. The trend magnitude is then expressed as a percentage change over the 57 years relative to the 57 years mean value of the index.

Linear regression is one of the simplest methods to calculate the trend of data in time series. The equation of the linear regression line is given by $Y=a+b X$, where $X$ is the independent variable and $Y$ is the dependent variable. The slope line is $b$, and $a$ is the intercept (value of $Y$ when $X=0$ ). The slope of regression describes whether the trend is positive or negative. In this study, $Y$ is the precipitation and $X$ is the year. Linear regression requires the assumption of normal distribution. In this study, the null hypothesis is that the slope of the line is zero or there is no trend in the data. The significance of the slope is shown by the probability value ( $P$-value) of it. Microsoft Excel was used to calculate the lines and statistical values of linear regression analysis. The $P$-value from the analysis is the test for the significant level $a=0.05$. In the 'linear' case, statistical significance is assessed following the nonparametric Kendall's tau test (Kendall, 1970). This is a robust, rank-based test, which, unlike the conventional Student's $t$-test, does not depend on the assumption of Gaussian distributed residuals.

Kendall's tau differs from the Spearman rank-order correlation in that it only uses the relative ordering of ranks when comparing points. It is calculated over all possible pairs of data points using the following formula:

$$
\tau=\frac{\text { concordant }- \text { discordant }}{\sqrt{\text { concordant }+ \text { discordant }+ \text { sameX }} \sqrt{\text { concordant }+ \text { discordant }+ \text { sameY }}},
$$

where concordant is the number of pairs where the relative ordering of $X$ and $Y$ are the same, discordant where they are the opposite, same $X$ where the $\mathrm{x}$ values are the same, and same $Y$ where the $Y$ values are the same. $\tau$ is approximately normally distributed with zero mean and variance:

$$
\operatorname{Var}(\tau)=\frac{4 N+10}{9 N(N-1)}
$$

One advantage of Kendall's tau over the Spearman coefficient is the problem of assigning ranks when data are tied. Kendall's tau is only concerned whether a rank is higher or lower than the other, and, therefore, it can be calculated by comparing the data themselves rather than their rank. When data are limited to only a few discrete values, Kendall's tau is a more suitable statistic.

For indices with a discrete value range, e.g., for counts of threshold exceedances and frequencies, we used logistic regression for trend calculation. Logistic regression is a special case of the generalization of regression techniques (see McCullagh and Nelder, 1989). It is appropriate for dealing with number 
counts and probabilities, for which the assumptions of linear regression with uniform variance and Gaussian residuals are not satisfied. The logistic regression approach of this paper is similar to the application in Frei and Schär (2001). In particular, we used the logit function as a link function and the maximum likelihood method for parameter estimation. Moreover, in the assessment of statistical significance, we corrected for overdispersion in the data series, which is an implicit account of the serial correlation in the annual series. Our calculations are based on the software MATLAB, where slightly different formal approaches are needed for counts compared with probabilities (see also Venables and Ripley, 1997). Indices for which trends are calculated and tested by logistic regression are labeled as logit.counts and logit.probs in Table 1.

Frei and Schär (2001) suggest the use of binomial distribution to model the count $n$ of events at a particular time (e.g., the number of heavy daily precipitation in a particular summer). The probability for $n$ events in $m$-independent trials (days) is given by

$$
B(n ; \pi, m)=\left(\begin{array}{c}
m \\
n
\end{array}\right) \pi^{n}(1-\pi)^{m-n}
$$

with

$$
\left(\begin{array}{c}
m \\
n
\end{array}\right)=\frac{m !}{n !(m-n) !}
$$

where $\pi$ is the probability of the event occurrence. The expected value $\langle n\rangle$ and variance $\operatorname{var}\langle n\rangle$ of the distribution are

$$
\langle n\rangle=m \pi, \quad \operatorname{var}(n)=m \cdot \pi \cdot(1-\pi) .
$$

The logistic regression model expresses a transformed form of the expected value of counts (or equivalently the event probability $\pi$ ) as a linear of a covariate $x$ :

$$
\eta(\pi)=\alpha+\beta \cdot t
$$

where $t$ is the time, $\alpha$ and $\beta$ are the regression intercept and coefficient, respectively, to be estimated from the data $\eta$ is a prescribed link function that transfers the value range of $\pi \hat{\mathrm{I}}[0,1]$ on to the real axis, to ensure compatibility with the linear model on the right hand side of Eq. (6). In principle, various link functions can be appropriate. Here we chose the canonical link of the logistic regression model: 


$$
\eta(x)=\operatorname{logit}(\mathrm{x}) \equiv \log \left(\frac{x}{1-x}\right) .
$$

As a result, the connection between the expected value of events and the covariate takes the form:

$$
\pi(t ; \alpha, \beta)=\exp (\alpha+\beta \cdot t) /[1+\exp (\alpha+\beta \cdot t] .
$$

The magnitude of the trend, as given by model parameter $\beta$, is conveniently expressed as the odds ratio $\Theta$, defined as

$$
\Theta \equiv \frac{\pi\left(t_{2}\right)}{1-\pi\left(t_{2}\right)} / \frac{\pi\left(t_{1}\right)}{1-\pi\left(t_{1}\right)}=\exp \left[\beta \cdot\left(t_{2}-t_{1}\right)\right] .
$$

The odds ratio represents the relative change in the ratio of the events against nonevents during the period $\left(t_{1}, t_{2}\right)$, and it is an exponential function of the period length. In the case of rare events $(\pi \ll 1)$, Eq.(5) approximates an exponential trend and the odds ratio represents the fractional change of the rare event probability from the beginning to the end of the period $\left[\Theta \approx \pi\left(t_{2}\right) / \pi\left(t_{1}\right)\right]$.

The parameters $\alpha$ and $\beta$ of logistic regression model are estimated using an S-plus implementation of the maximum likelihood method (Zarenistanak et al., 2014). The statistical significance of the estimated trend parameter can be inferred from the $p$-value testing against the null hypothesis $(\beta=0)$. (The $p$-value represents the probability of accepting the null hypothesis). In our applications, $p$-values were obtained by using the deviance difference between the trend model and the null hypothesis as the test statistic (McCullagh and Nelder, 1989). Test results will be given for a two-tailed test with a significance level of $5 \%$.

For convenience in displaying the results, the trend magnitudes derived by logistic regression are converted into relative changes over the 57 years as for linear regression. Yet it should be noted that trend magnitudes between the two regression methods are not strictly comparable. For example, the change in the probability of a threshold exceedance differs from the respective change in the threshold (e.g., Katz and Brown, 1970; Fowler and Hennessy, 1995).

\section{Results and discussion}

First, precipitation indices (Table 1) were calculated for spatial precipitation networks (Fig. 1) in annual and seasonal scales, the trend of which was later analyzed based on the trend estimation method (the last column in Table 1). Finally, a more precise analysis of their spatial and temporal variability during the last half-century was performed. 


\subsection{Annual Trend}

Fig. 2 shows the spatial distribution of the results related to the annual trend for heavy precipitation group indices in the studied area. These results are presented for the first 5 indices in Table 1 as follows: (1)pq90 and pq95, (2) pnl85 and pn190, (3) pfl90, (4) px3d, px4d, and px5d, and (5) pn5mm. Also, the spatial distribution of the significance levels of this trend for these indices along with the base precipitation group indices are presented in Fig. 5.
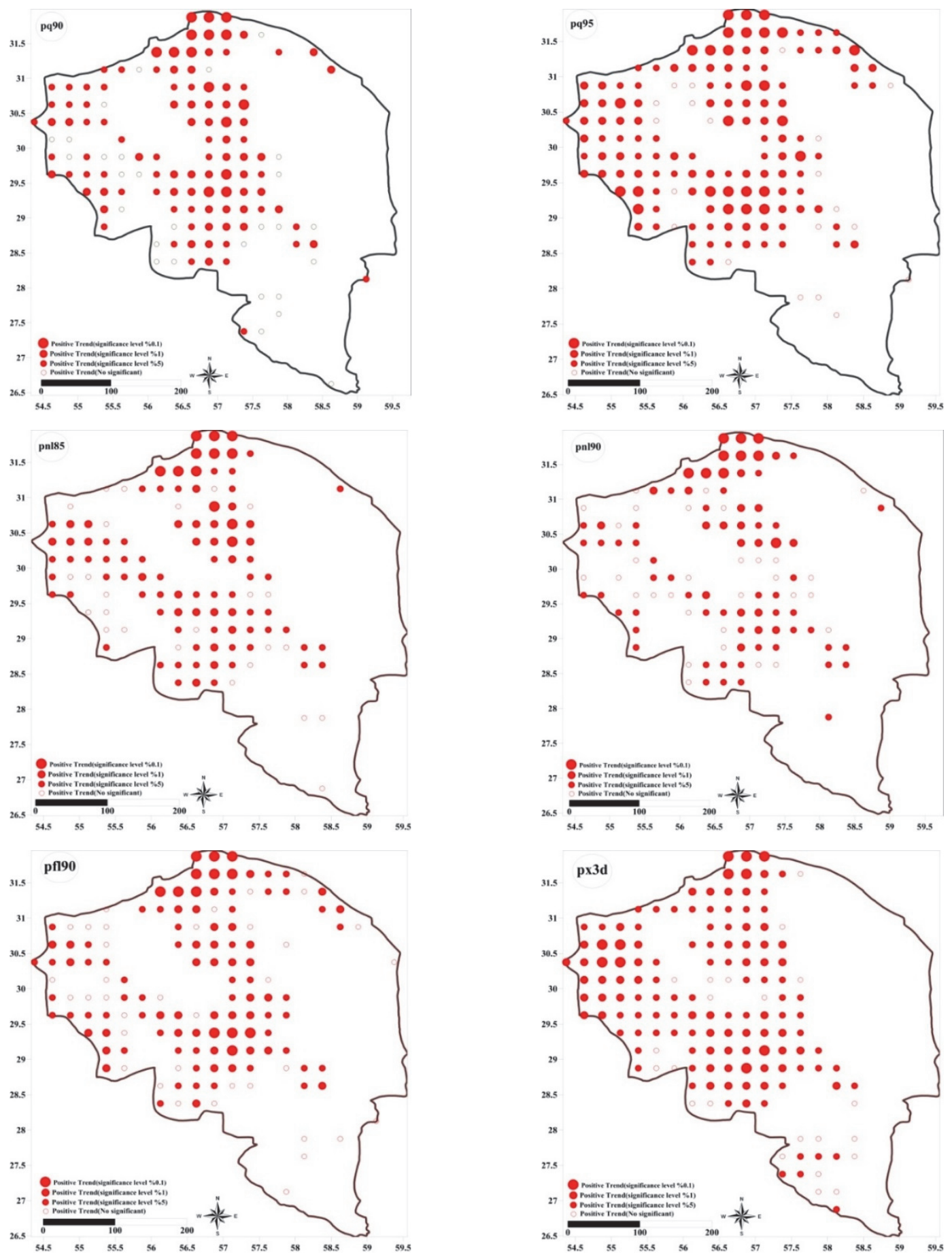


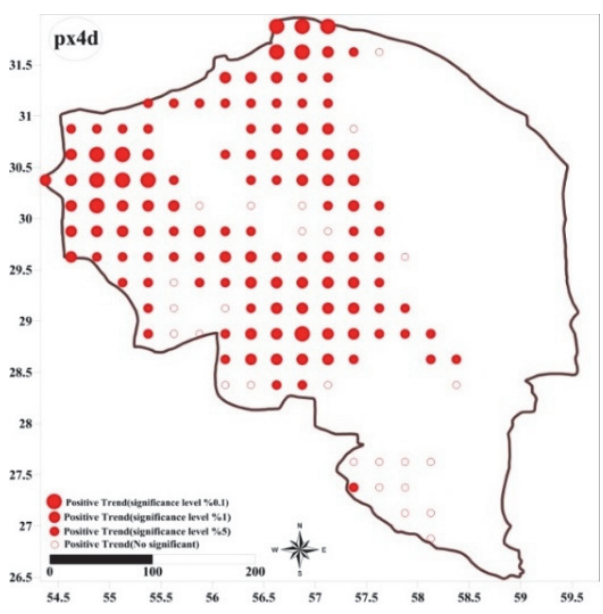

Fig. 2. Annual trends of the heavy precipitation indices. ( $p q 95$ and $p q 90$ : heavy precipitation threshold; pnl85 and pnl90: heavy precipitation day; pfl90: heavy precipitation proportion; $p \times 3 d, p \times 4 d$ and $p \times 5 d$ : greatest $N$-day precipitation; pn5mm: heavy precipitation frequency)
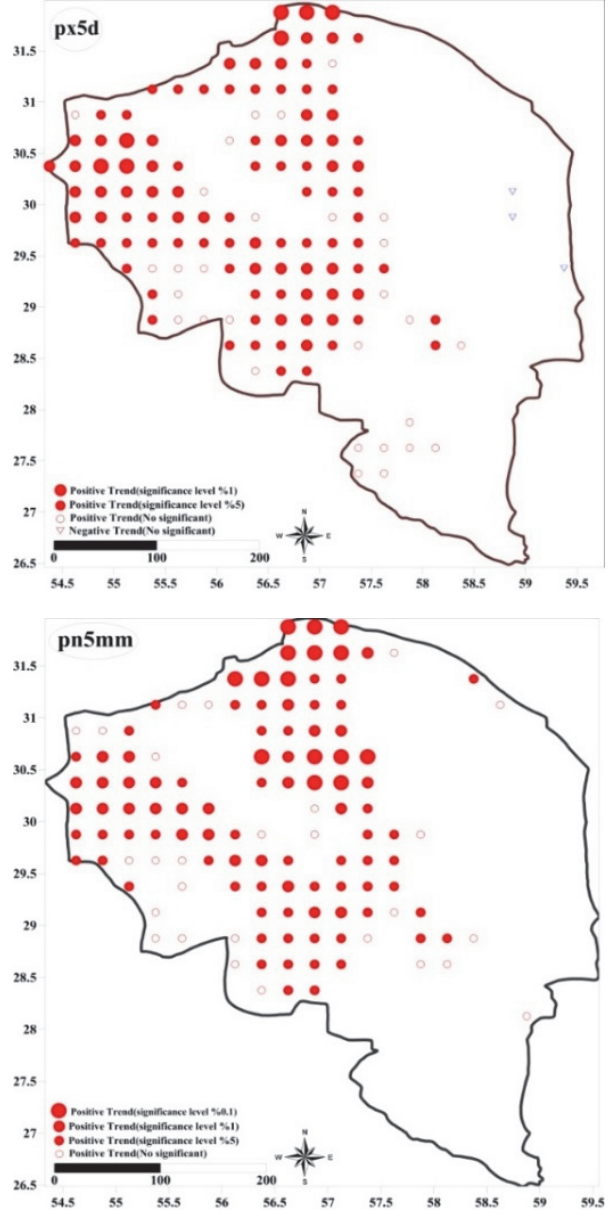

In the annual scale (Fig. 2), trend analysis reveals a similar trend for all of the heavy precipitation indices. All of these indices show an evident bump for the positive-trend estimates (circles as opposed to triangles), which is significant in a large number of the network pixels (filled symbols). The greatest incremental trend is observed in the heavy precipitation frequency and threshold indices at a very high significance level $(0.01 \%)$. At the high significance level (1\%), indices of heavy precipitation days, heavy precipitation threshold, and maximum n-day precipitation had a large range. At the average significance level (5\%), all the heavy precipitation indices had a large range. Thus, the incremental trend range was maximum at a 5\% significance level compared with other levels. The geographical scope of the areas with the incremental trend in heavy precipitation indices matched the spatial distribution of the uneven areas (Fig. 4). Therefore, considering the characteristics of mountainous areas such as high slope and low permeability, the probability of increasing floods and their future effects is increased. 


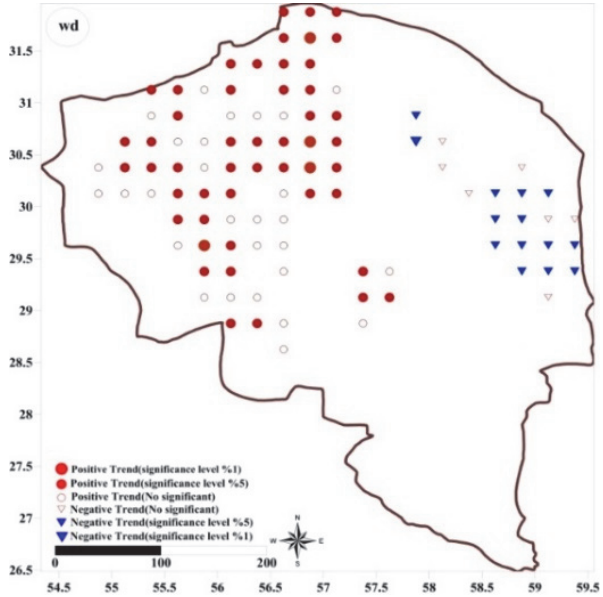

Fig. 3. Annual trends results of basic precipitation indices $(w d$ : frequency of wet day; pav: precipitation average, and pint: simple daily intensity).
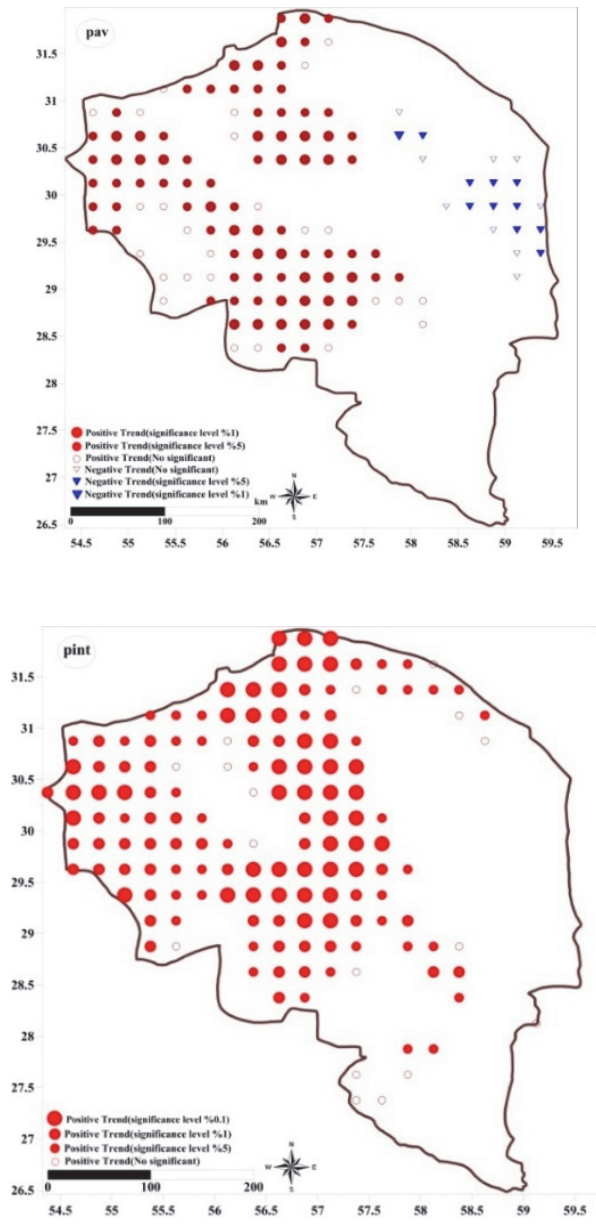

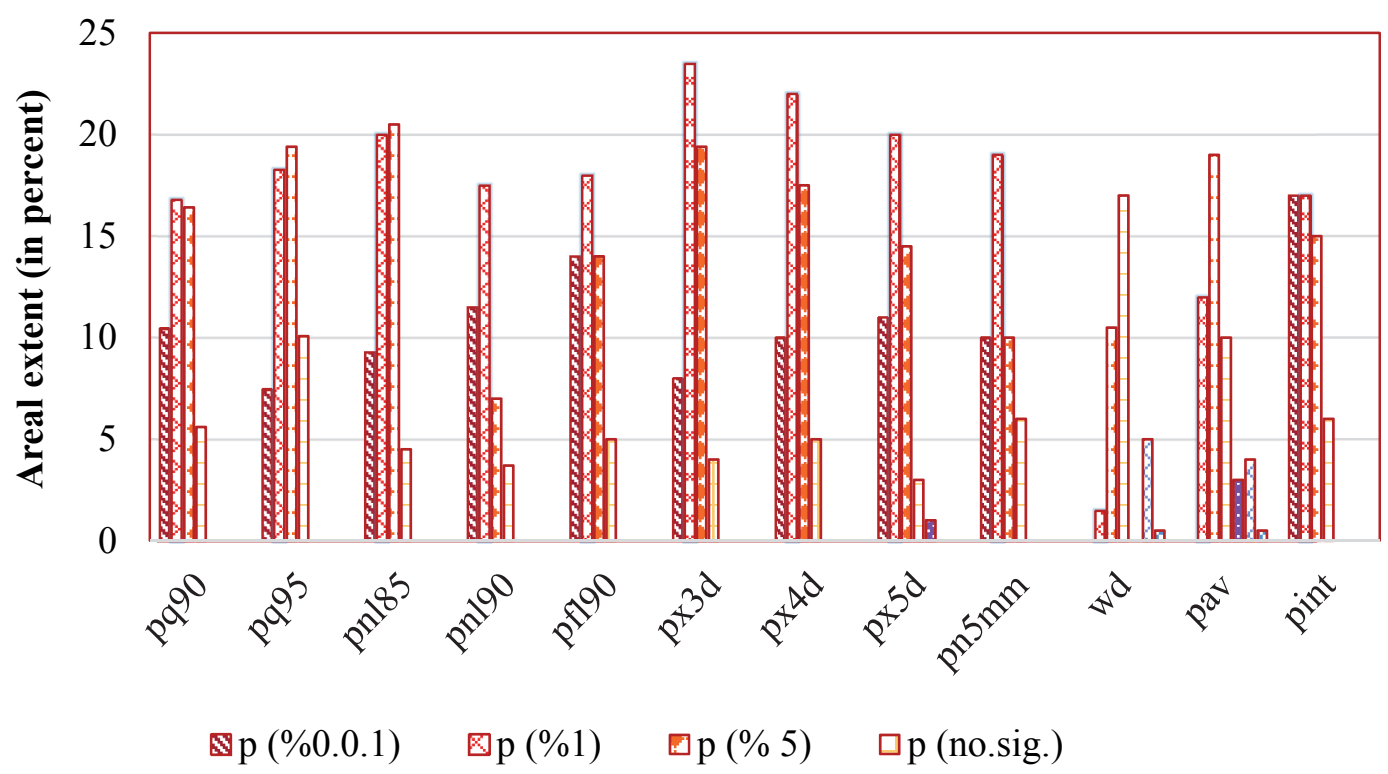

Fig. 4. The areal extent of statistical significance levels in the annual trend of heavy and basic precipitation indices ( $\mathrm{p}$ and $\mathrm{n}$ are respectively positive and negative trend symbols). 


\subsection{Seasonal trend}

Fig. 5 demonstrates the spatial distribution of seasonal precipitation for a long period in the studied area. The precipitation regime was of winter and spring nature in the studied area. In other words, winter and spring had maximum share in supplying the annual precipitation. Thus, probable changes in the indices of heavy and base precipitation groups were investigated for these two seasons (Nazaripour and Daneshvar, 2017).
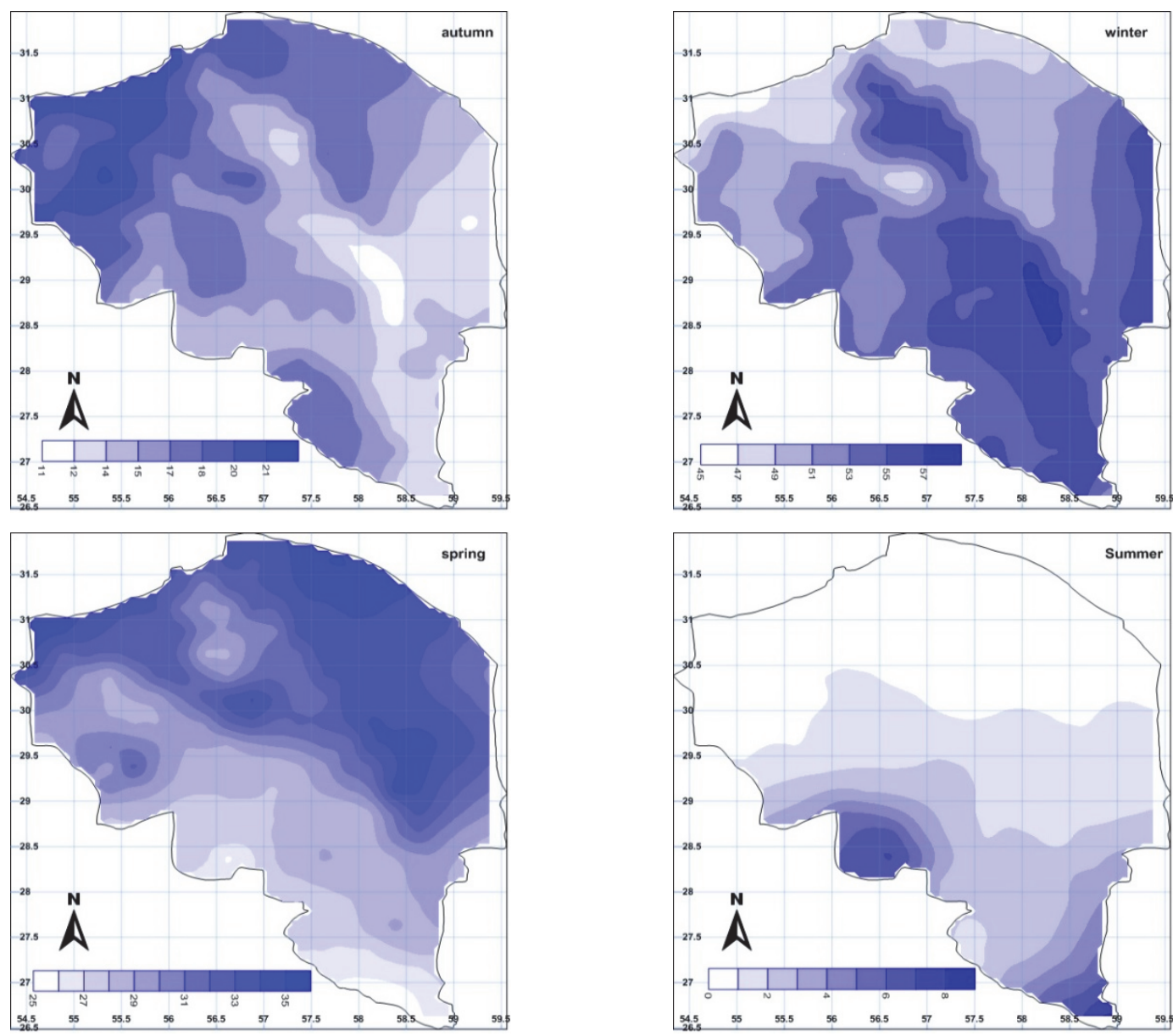

Fig. 5. Spatial distribution of seasonal precipitation in the study area, that was obtained by surface interpolation (kriging method) of the long-term mean of seasonal precipitation.

Fig. 6 shows the results of the trend for the heavy precipitation indices in winter for the studied area. The trend analysis found a similar trend for all of the heavy precipitation indices in winter. Results of the statistical and spatial trend analysis represented a clear positive trend with statistical significance in a large 
part of the studied area. The geographical scope of the regions with a trend in winter was in full agreement with the annual scale. In other words, the variability of heavy precipitation indices was associated with winter as the region with maximum precipitation. The geographical scope of the areas with the incremental trend in heavy precipitation indices matched the spatial distribution of uneven areas. The largest scope of very high statistical significance $(0.01 \%)$ in heavy precipitation indices associated with winter was observed in the greatest n-day precipitation indices and heavy precipitation ratio. At a high significance level $(1 \%)$, the scope of each heavy precipitation indices was high. At the medium significant level (5\%), heavy precipitation threshold indices, heavy precipitation days, and the greatest $\mathrm{n}$-day precipitation had a large scope. The spatial range of the statistical insignificance level was minimum compared with the other levels(Fig. 8). More precise analysis of the spatial distribution of significance levels related to the incremental trend in the heavy precipitation indices showed that the incremental trend of these indices was very significant in winter.
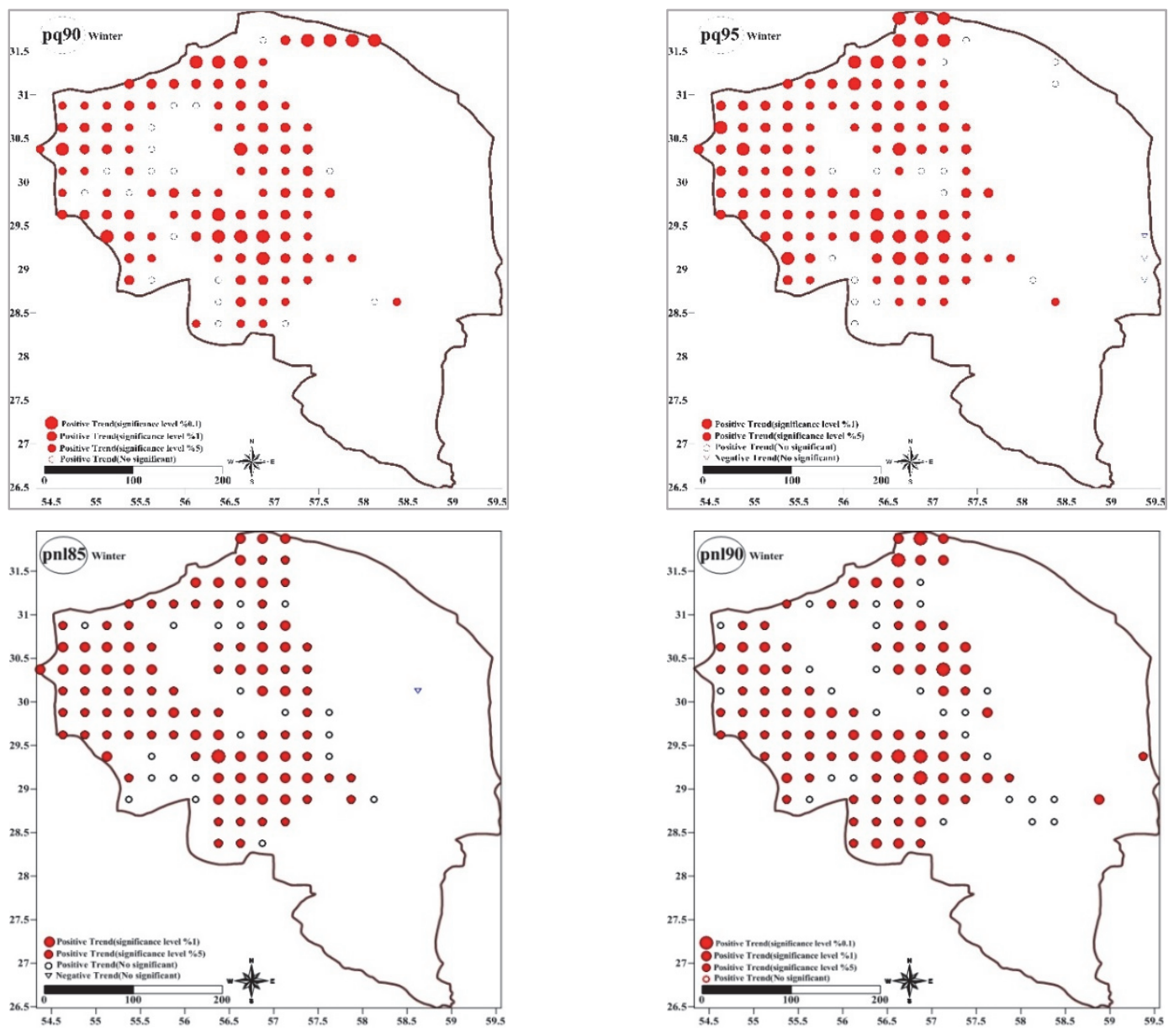

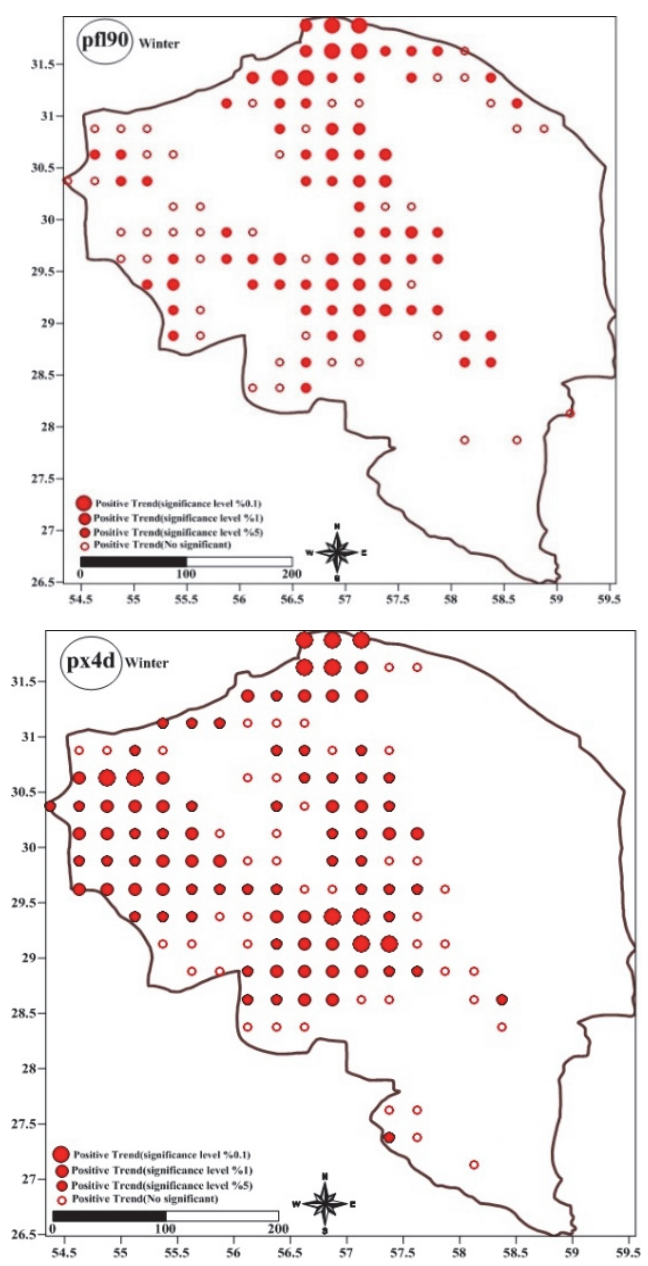

Fig. 6. Winter trend of the heavy precipitation indices. ( $p q 95$ and $p q 90$ : heavy precipitation threshold; pnl85 and pnl90: heavy precipitation day; pfl90: heavy precipitation proportion;px3d, px4d, and px5d: greatest $N$-day precipitation; pn $5 \mathrm{~mm}$ : heavy precipitation frequency)
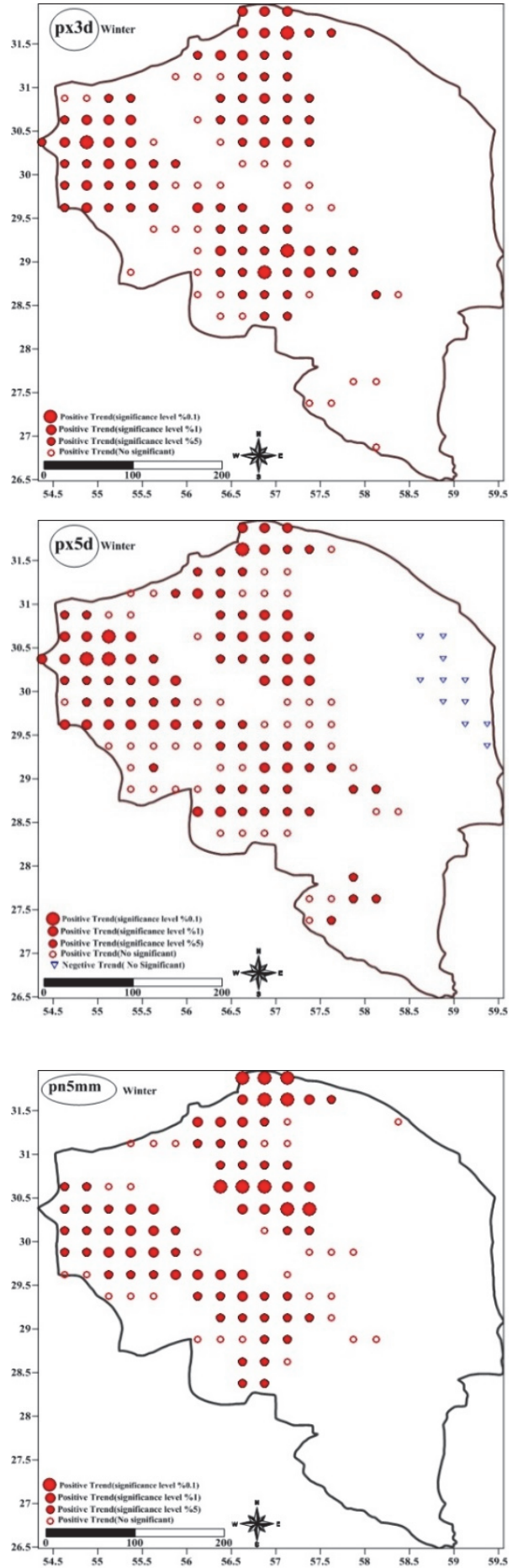

Fig. 7 shows the trend of the base precipitation group indices for winter. Similar to the annual scale, the precipitation intensity index showed a clear bump in the incremental trend. The maximum spatial scope for the precipitation intensity index was at average, high, and very high significance levels, 
respectively. Conversely, the two other indices of the base precipitation group did not show the same trend. A significant incremental trend in the relatively large spatial scope was observed in rainy days and average precipitation indices, which was limited to the eastern part of the studied area. On the other hand, a decremental trend was observed at the average significance level in these indices. The spatial range of this decremental trend was limited to two areas. One was the eastern half situated on the edge of Dasht-e Lut desert and the other was located on the southern corner in Jazmurian wetland, both of which had very low precipitation.

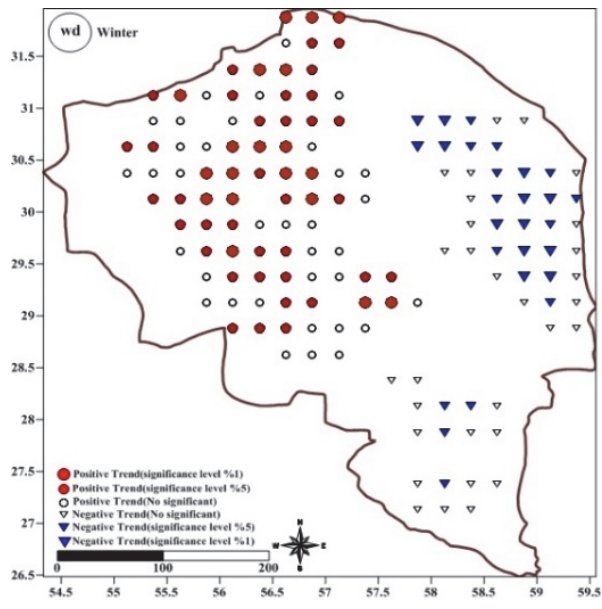

Fig. 7. Winter trends of the basic precipitation indices ( $w d$ : frequency of wet day; pav: precipitation average, and pint: simple daily intensity).
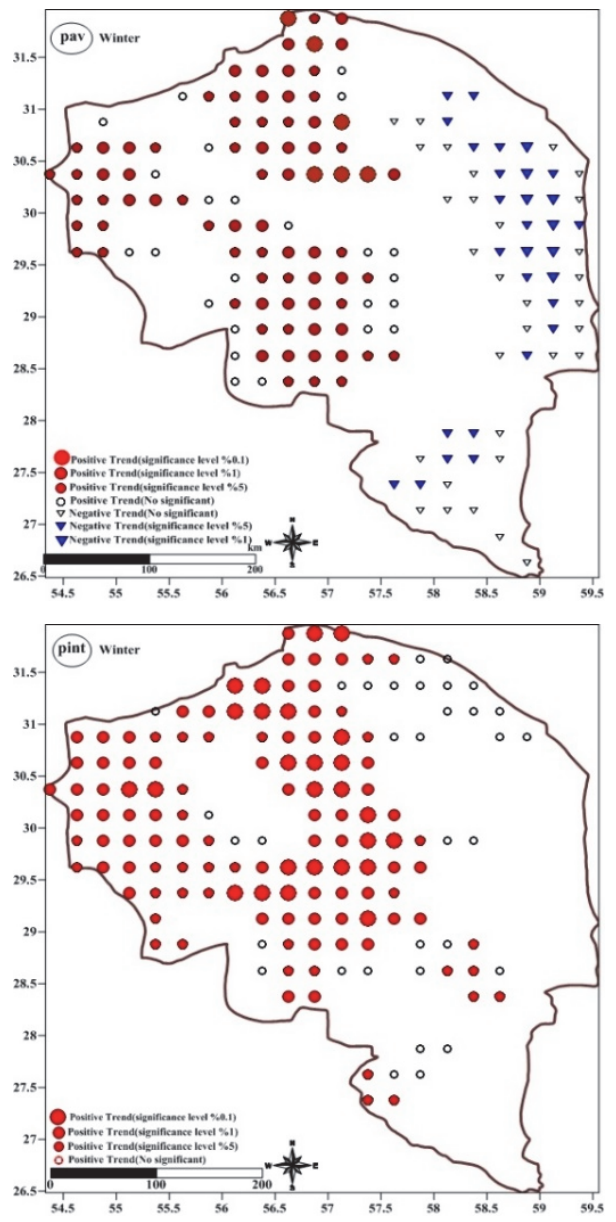


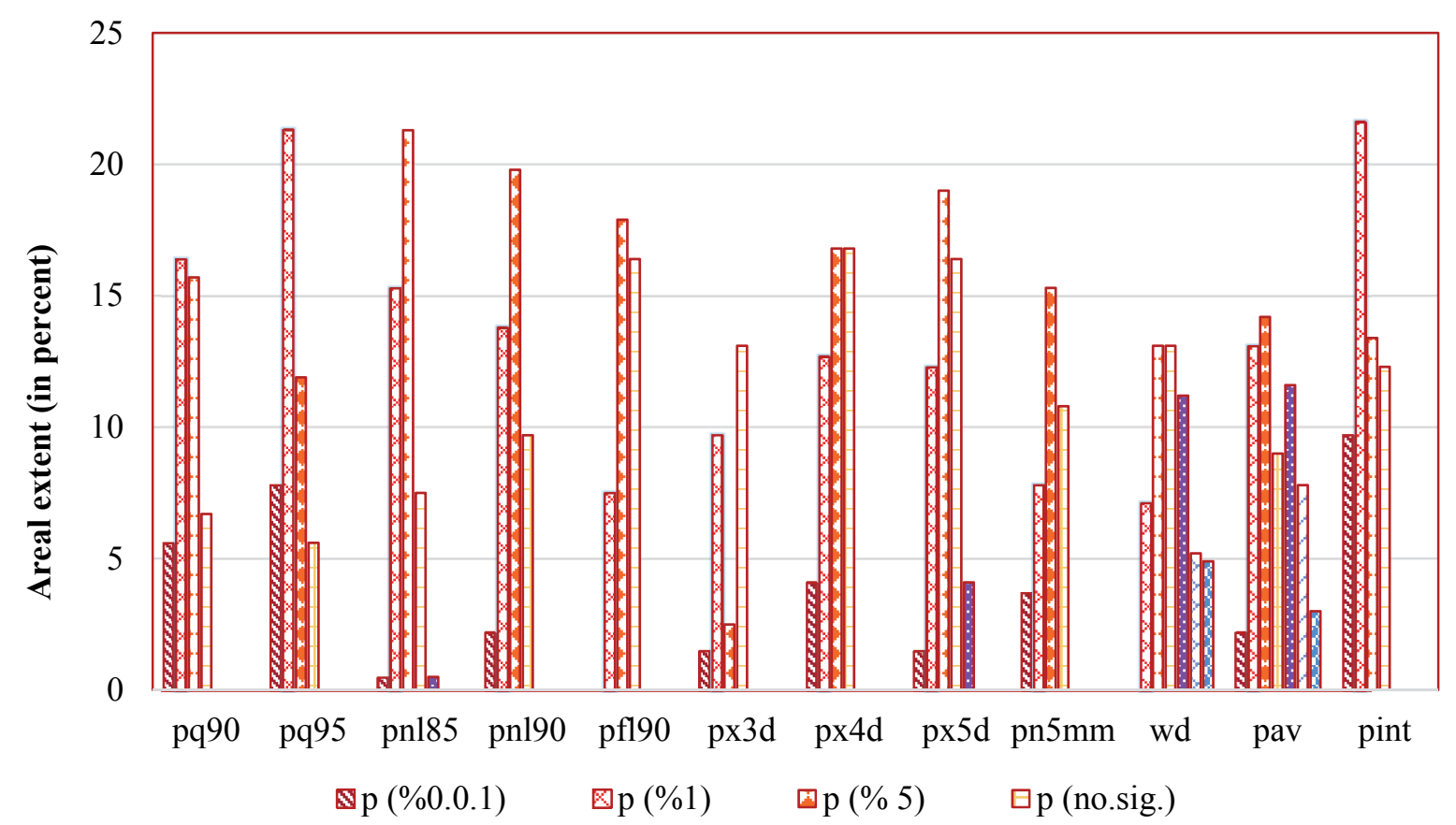

Fig. 8. The areal extent of statistical significance levels in the winter trend of heavy and basic precipitation indices ( $\mathrm{p}$ and $\mathrm{n}$ are respectively positive and negative trend symbols).

Fig. 9. shows the trend of the heavy precipitation group indices in spring. Unlike the annual scale and winter, the only indices that had a trend were heavy precipitation threshold, heavy precipitation days, and heavy precipitation ratio, the trends of which were not the same. Results of statistical and trend analyses indicated an incremental trend in the northern half and a decremental one in the southern half of the studied area. The spatial range of the incremental trend was more than that of the decremental one. Nevertheless, the trends were not highly significant (Figy. 11). Temporal and spatial variability in spring compared with winter could justify the lack of spatial uniformity in the trend. In contrast to winter, the maximum precipitation of spring was limited to the northern half of the studied area. Thus, the incremental trend of heavy precipitation indices in spring matched the maximum spatial distribution of precipitation in this season.

Fig. 10 represents the trend of base precipitation indices for spring. The average precipitation index showed a clear trend in the northern half of the studied area, the highest scope of which was located in the eastern part of the area and the edge of Dasht-e Lut. Rainy day index had an incremental trend as well, but it was less statistically and spatially significant. Also, precipitation intensity index was less statistically and spatially significant in the studied area. 

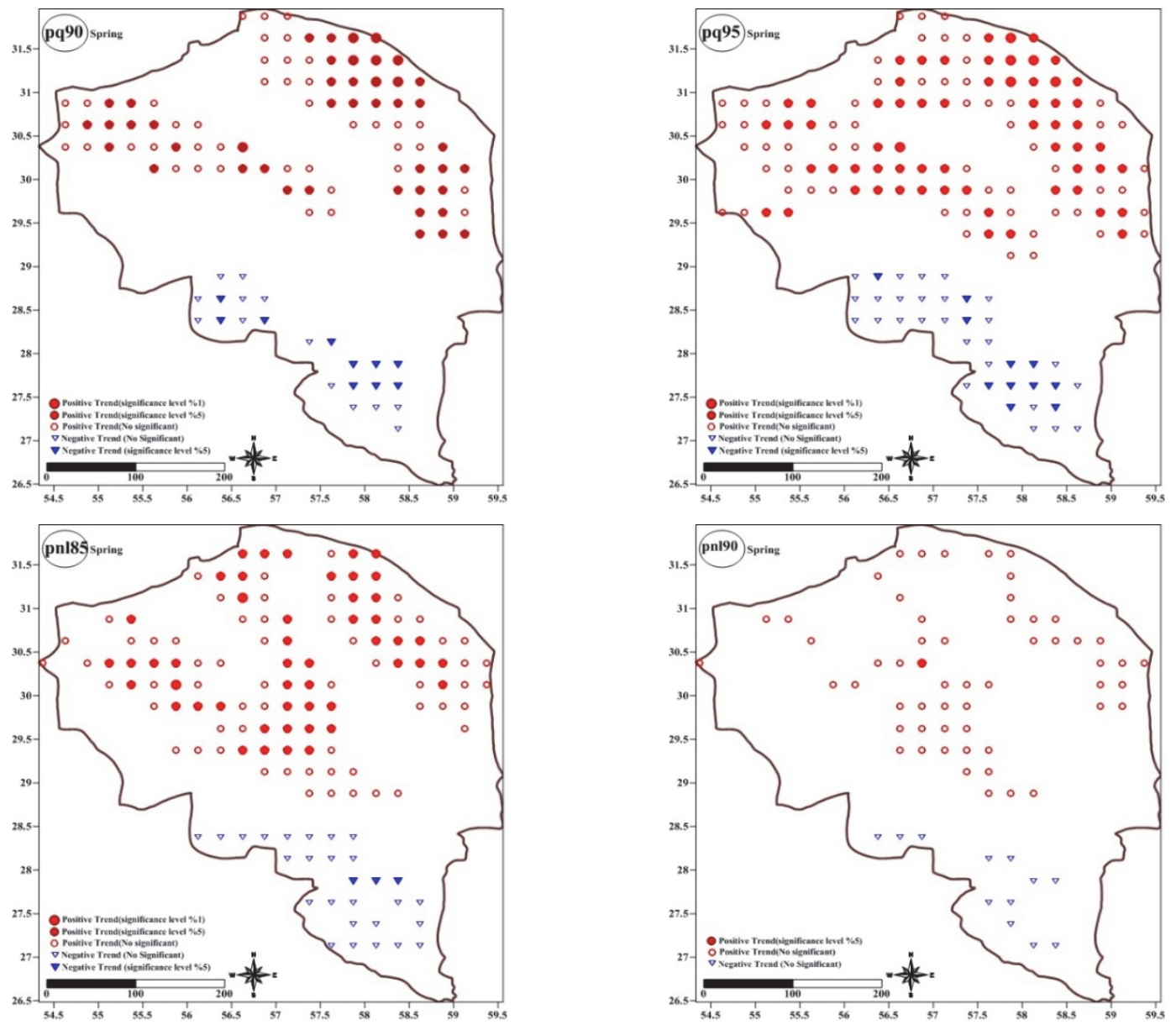

Fig. 9. Spring trends of the heavy precipitation indices The $\mathrm{px} 3 \mathrm{~d}, \mathrm{px} 4 \mathrm{~d}$, px $5 \mathrm{~d}$ and $\mathrm{pn} 5 \mathrm{~mm}$ indices are without any trend.

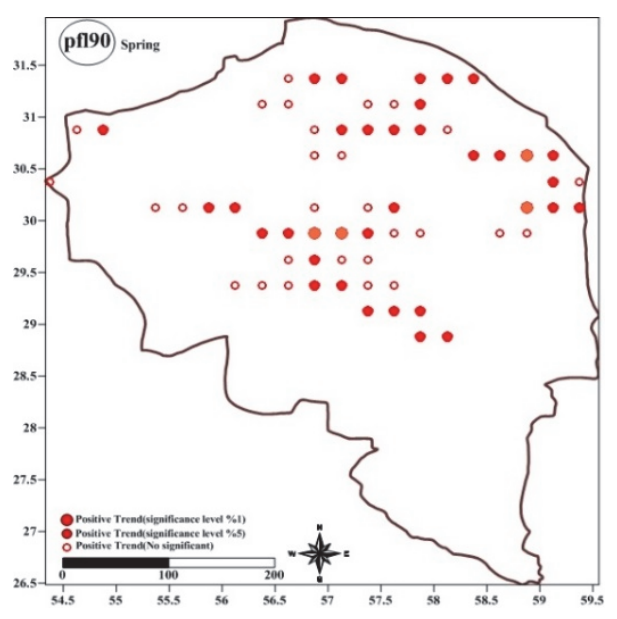




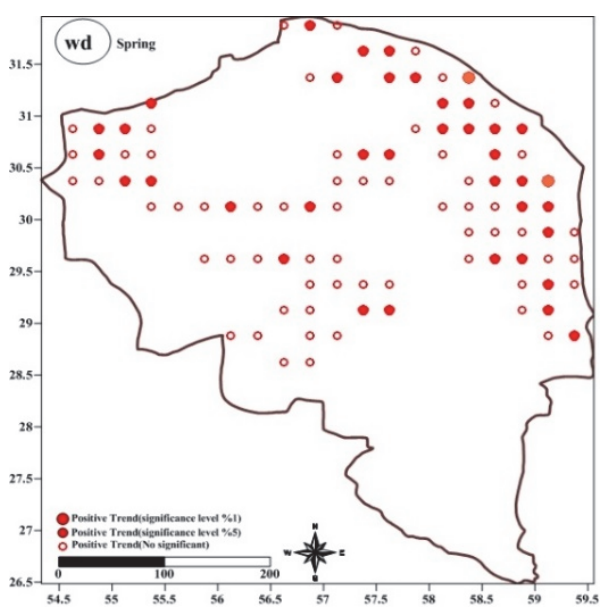

Fig. 10. Spring trends of the basic precipitation indices $(w d$ : frequency of wet day; pav: precipitation average, and pint: simple daily intensity).
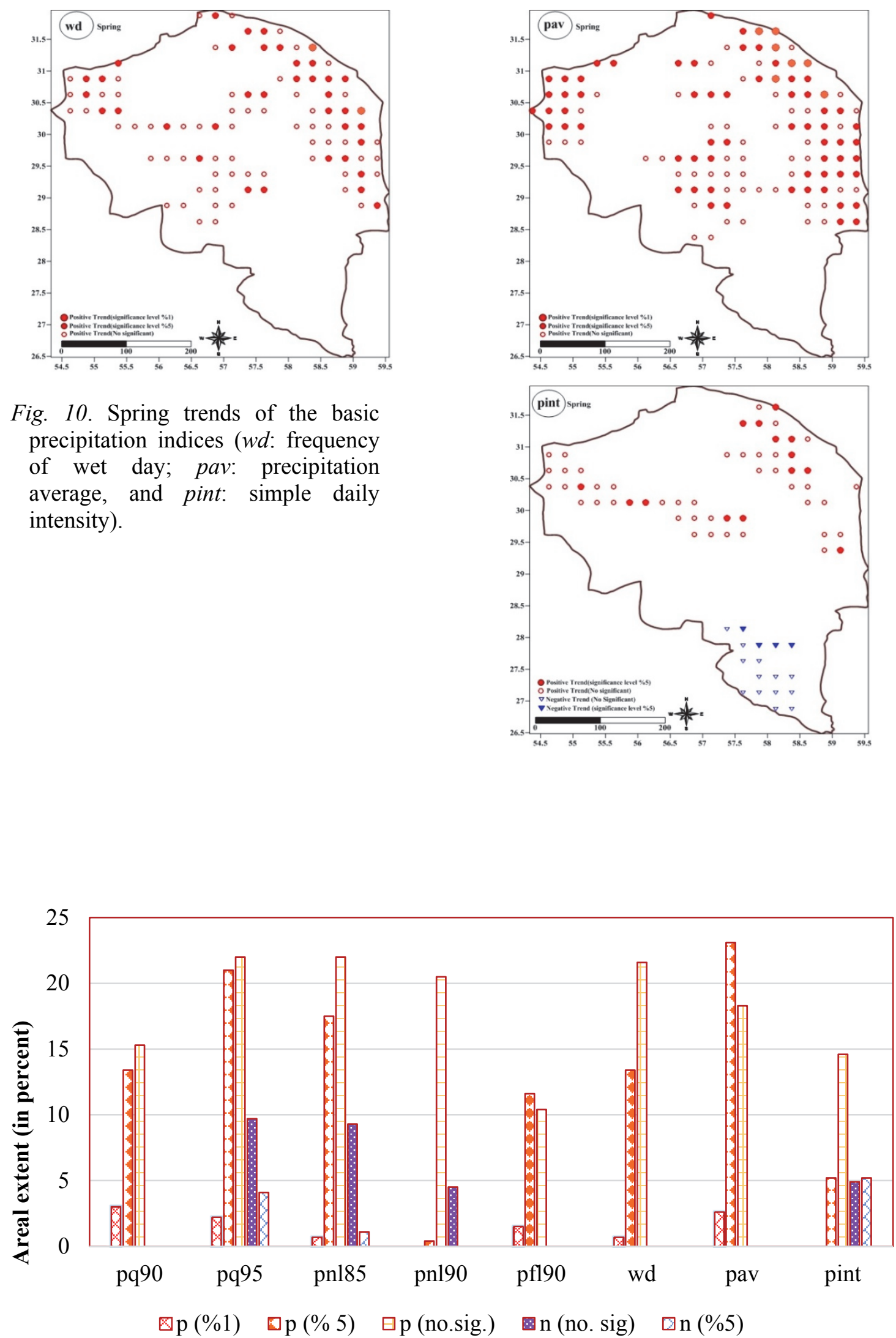

Fig. 11. As Fig. 8, but for spring. The areal extent of statistical significance levels in the spring trend of heavy and basic precipitation indices ( $\mathrm{p}$ and $\mathrm{n}$ are respectively positive and negative trend symbols). 


\section{Conclusions}

In this study, we have analyzed daily precipitation data from the dense network in one of the arid and semi-arid regions of Iran for trends in daily precipitation statistics over the last half-century. The statistics encompass basic characteristics and measures of heavy precipitation. Two different methods of trend analysis and statistical assessment were applied, depending on the data nature of the indices. Our analysis has identified spatially coherent and statistically significant trends for most statistics related to the heavy precipitation category.

In the annual scale, a statistically significant and spatially coherent incremental trend was observed for all the indices of heavy precipitation groups as well as the precipitation intensity index. The strong statistical significance of the incremental trend was more prominent in the indices related to the highlands and the studied mountainous area. These indices in the lowlands including the marginal land of the Dasht-e Lut desert in the east and the south-east desert of Jazmurian wetland in the studied area lacked any trend. The incremental trend of the heavy precipitation indices was considered a climatic warning in the high and mountainous lands, which are flood-prone. There was also an incremental trend, both statistically and spatially, in heavy precipitation indices of winter and spring, which was the same as the annual scale. However, there were differences in the statistical and spatial characteristics between the two seasons. In winter, an almost identical change was found in each heavy precipitation group indices as well as in the precipitation intensity index of the base precipitation group. However, in spring, the situation was more complicated. Here, there was variability in some indices of the heavy precipitation category including heavy precipitation threshold, heavy precipitation days, and heavy precipitation ratio. The variability of spring indices was not statistically and spatially significant. In other words, a large volume of the annual variation of heavy variability indices could be explained by the winter season. In autumn and summer, the heavy precipitation indices did not show statistically significant trends, and there was no evidence for long-term trends in the statistics related to the basic precipitation category.

\section{References}

Abbaspour, K.C., Faramarzi, M., Ghasemi, S.S., and Yang, H., 2009: Assessing the impact of climate change on water resources in Iran. Water Resour. Res. 45, W10434.

https://doi.org/10.1029/2008WR007615

Abolverdi, J., Ferdosifar, G., Khalili, D., and Kamgar-Haghighi, A.A., 2016: Spatial and temporal changes of precipitation concentration in Fars province, southwestern Iran. Meteorol. Atmosph. Phys 128, 181-196. https://doi.org/10.1007/s00703-015-0414-0

Abolverdi, J., Ferdosifar, G., Khalili, D., Kamgar-Haghighi, A.A., and Haghighi, M.A., 2014: Recent trends in regional air temperature and precipitation and links to global climate change in the Maharlo watershed, Southwestern Iran. Meteorol. Atmosph. Phys 126, 177-192.

https://doi.org/10.1007/s00703-014-0341-5 
Alijani B., 2007: Time series analysis of daily rainfall variability and extreme events. 10th International Meeting on Statistical Climatology, Beijing, China.

Alijani, B., O'brien, J., and Yarnal, B., 2008: Spatial analysis of precipitation intensity and concentration in Iran. Theor. Appl.Climatol. 94, 107-124. https://doi.org/10.1007/s00704-007-0344-y

Amiri, M.J. and Eslamian, S.S., 2010: Investigation of climate change in Iran. J Environ Sci Technol, 3, 208-216. https://doi.org/10.3923/jest.2010.208.216

Climatic Research Unit, 2005: STARDEX: Statistical and Regional dynamical Downscaling of Extremes for European regions [Internet]. Climatic Research Unit; [cited 2011 Sep 9]. Available from: http://www.cru.uea.ac.uk/projects/star-dex/

Darand, M., Nazaripour, H., and Daneshvar, M.M., 2015: Spatial and temporal trend analysis of temperature extremes based on Iranian climatic database (1962-2004). Arabian J. Geosci. 8, 8469-8480. https://doi.org/10.1007/s12517-015-1840-5

Das, H.P., Adamenko, T.I., Anaman, K.A., Gommes, R.G., and Johnson, G.. 2003: Agrometeorology related to extreme events. World Meteorological Organization, Technical Note No 201.

Dhorde, A.G., Zarenistanak, M., Kripalani, R.H., and Preethi, B., 2014: Precipitation analysis over southwest Iran: trends and projections. Meteorol. Atmosph. Phys. 124, 205-216. https://doi.org/10.1007/s00703-014-0313-9

Dinpashoh, Y., Fakheri-Fard, A., Moghaddam, M., Jahanbakhsh, S., and Mirnia, M., 2004: Selection of variables for the purpose of regionalization of Iran's precipitation climate using multivariate methods. J. Hydrol. 297, 109-123. https://doi.org/10.1016/j.jhydrol.2004.04.009

Fowler, A.M. and Hennessy, K.J., 1995: Potential impacts of global warming on the frequency and magnitude of heavy precipitation. Nat. Hazards 11, 282-303. https://doi.org/10.1007/BF00613411

Frei. C. and Schär, C.. 2001: Detection probability of trends in rare events: theory and application of heavy precipitation in the Alpine region. J. Climate 14, 1568-1584. https://doi.org/10.1175/1520-0442(2001)014<1568:DPOTIR >2.0.CO;2

Ghahraman, B. and Taghvaeian, S. 2010: Investigation of annual rainfall trends in Iran. J. Agric. Scie. Technol. 10, 93-97.

Hamada, A., Arakawa, O., and Yatagai, A., 2011: An automated quality control method for daily raingauge data. Glob. Environ. Res, 15, 183-192.

Hasaniha, H.A. and Meghdadi, M., (2010: The Analysis of Spring Precipitation in Semi-Arid Regions: Case Study in Iran. J. Water Res. Protect. 2, 69. https://doi.org/10.4236/iwarp.2010.21008

IWRMC, 2006: Draft of Flood damage assessment, Bulletin A. 296, Ministry of Energy. (In Persian)

Katz, R.W. and Brown, B.G., 1992: Extreme events in a changing climate: variability is more important than averages. Climatic Change 21, 289-302. https://doi.org/10.1007/BF00139728

Kendall, M.G., 1970: Rank Correlation Methods, 4th edn. London: Griffin.

Marofi, S., Sohrabi, M.M., Mohammadi, K., Sabziparvar, A.A., and Abyaneh, H.Z., 2011: Investigation of meteorological extreme events over coastal regions of Iran. Theor. Appl. Climatol. 103, 401412. https://doi.org/10.1007/s00704-010-0298-3

McCullagh, P. and Nelder, J.A., 1989: Generalized Linear Models. Monographs on Statistics and Applied Probability, 37, 2nd edn. Chapman and Hall: London.

Modarres, $R$. and Sarhadi, A., 2009: Rainfall trends analysis of Iran in the last half of the twentieth century. J. Geophys. Res.: Atmosph. (1984-2012), 114(D3). https://doi.org/10.1029/2008JD010707

Molanejad, M. and Ranjbar, A., 2014: Climatic Extreme Events over Iran: Observation and Future Projection, 3 rd Meeting of COMSATS' International Thematic Research Group on 'Climate Change and Environmental Protection, Islamabad, Pakistan.

Molanejad, M., Soltani, M., and Ranjbar, A., 2014: Changes in precipitation extremes in climate variability over northwest Iran. Int. J. Agric. Policy. Res. 2, 334-345.

Nazaripour, H., and Daneshvar, M.M., 2014. Spatial contribution of one-day precipitations variability to rainy days and rainfall amounts in Iran. Int. J. Environ. Sci. Technol. 11, 1751-1758.

https://doi.org/10.1007/s13762-014-0616-x 
Nazaripour, H., \& Daneshvar, M. R. M. 2017. Rain gauge network evaluation and optimal design using spatial correlation approach in arid and semi-arid regions of Iran. Theoretical and Applied Climatology, 129(3), 1255-1261.

Nicholls, N. and Murray, W., 1999: Workshop on indices and indicators for climatic extremes: Asheville, NC, USA, 3-6 June 1997 Breakout Group B: precipitation. Climatic change 42: 23-29. https://doi.org/10.1007/978-94-015-9265-9_4

Nicholls, M., Gruza, G.W., Jouzel, J., Karl, T.R., Ogallo, L.A., and Parker, D.E., 1996: Chapter 3, observed climate variability and change., In: Climate change 1995: the science of climate change. Contribution to Working Group I to IPCC SAR. (eds.: J.T. Houghton et al.,) Cambridge Univ. Press, 137-192.

Peterson, T.C., 2005: The workshop on enhancing south and central Asian climate monitoring and indices, Pune, India, February 14-19, 2005. CLIVAR Exch, 10(6).

Rahimzadeh, F., Asgari, A., and Fattahi, E., 2009: Variability of extreme temperature and precipitation in Iran during recent decades, Int. J. Climatol. 29, 329-343. https://doi.org/10.1002/joc.1739

Raziei, T., Bordi, I., and Pereira, L.S., 2008: A precipitation-based regionalization for eastern Iran and regional drought variability. Hydrol. Earth Syst. Sci. 12, 1309-1321. https://doi.org/10.5194/hess-12-1309-2008

Sabzevari, A.A., Zarenistanak, M., Tabari, H., and Moghimi, S., 2015: Evaluation of precipitation and river discharge variations over southwestern Iran during recent decades. J. Earth Syst. Sci. 124, 335-352. https://doi.org/10.1007/s12040-015-0549-x

Sohrabi, M.M., Ryu, J.H., and Alijani, B., 2013: Spatial and temporal analysis of climatic extremes over the mountainous regions of Iran. Int Climate Change 4(4), 19-36. https://doi.org/10.18848/1835-7156/CGP/v04i04/37183

Soltani, M., Laux, P., Kunstmann, H., Stan, K., Sohrabi, M.M., Molanejad, M., Sabziparvarm A.A., Ranjbar SaadatAbadi, A., Ranjbar, F., Rousta, I., Zawar-Reza, P., Khoshakhlagh, F., Soltanzadeh, I., Babu, C.A., Azizi, G.H., and Martin, M.V., 2016: Assessment of climate variations in temperature and precipitation extreme events over Iran. Theor. Appl. Climatol., 126, 775-795. https://doi.org/10.1007/s00704-015-1609-5

Tabari, H. and Talaee, P.H., 2011a: Analysis of trends in temperature data in arid and semi-arid regions of Iran. Glob. Planetary Change, 79, 1-10. https://doi.org/10.1016/j.gloplacha.2011.07.008

Tabari, H. and Talaee, P.H., 2011b. Temporal variability of precipitation over Iran: 1966-2005. J. Hydrol. 396, 313-320. https://doi.org/10.1016/j.jhydrol.2010.11.034

Tabari, H., Abghari, H., Tabari, H., and Talaee, P.H., Hosseinzadeh Talaee, P., 2012. Temporal trends and spatial characteristics of drought and rainfall in arid and semiarid regions of Iran. Hydrol. Process. 26, 3351-3361. https://doi.org/10.1002/hyp. 8460

Tabari, H. and Aghajanloo, M.B., 2013. Temporal pattern of aridity index in Iran with considering precipitation and evapotranspiration trends. Int. J. Climatol. 33, 396-409. https://doi.org/10.1002/joc.3432

Tabari, H., AghaKouchak, A., and Willems, P., 2014: A perturbation approach for assessing trends in precipitation extremes across Iran. J. Hydrol. 519, 1420-1427.

Tabatabai, A. and Hosseini, M., 2003: Investigation of climate change in Semman city by using monthly precipitation and averaged monthly temperatue (in Persian). Bureau of Meteorology of Semnan province, Third Regional and National Conference of Climate Change in Isfahan, 91-98.

Taghavi, F., 2010: Linkage between climate change and extreme events in Iran. J. Earth Space Physics $36(2), 33-43$.

Terink, $W$., Immerzeel, $W . W$., and Droogers, $P$., 2013: Climate change projections of precipitation and reference evapotranspiration for the Middle East and Northern Africa until 2050. Int. J. Climatol. 33, 3055-3072. https://doi.org/10.1002/joc.3650

UN, 2009: Global Assessment Report on Disaster Risk Reduction. United Nations, Geneva, Switzerland. http://www.preventionweb.net/english/hyogo/gar/report/.

Venables, W.N. and Ripley, B.D., 1997: Introduction. In: Modern Applied Statistics with S-PLUS. Springer New York. 1-18. https://doi.org/10.1007/978-1-4757-2719-7_1 
Yatagai, A., Kamiguchi, K., Arakawa, O., Hamada, A., Yasutomi, N., and Kitoh, A., 2012: APHRODITE: Constructing a long-term daily gridded precipitation dataset for Asia based on a dense network of rain gauges. Bull. Amer. Meteorol. Soc. 93, 1401-1415. https://doi.org/10.1175/BAMS-D-11-00122.1

Zarenistanak, M., Dhorde, A.G., and Kripalani, R.H., 2014: Trend analysis and change point detection of annual and seasonal precipitation and temperature series over southwest Iran. J. Earth Syst. Sci. 123, 281-295. https://doi.org/10.1007/s12040-013-0395-7

Zhang, X., Aguilar, E., Sensoy, S., Melkonyan, H., Tagiyeva, U., Ahmed, N., Kutaladze, N., Rahimzadeh, F., Taghipour, A., Hantosh, T.H., Albert, P., Semawi, M., Karam Ali, M., Halal Said Al-Shabibi, M., Al-Oulan, Z., Zatari, T., Al Dean Khelet, I., Hammoud, S., Sagir, R., Demircan, M., Eken, M., Adiguzel, M., Alexander, L., Peterson, T.C., and Wallis, T., 2005: Trends in Middle East climate extremes indices during 1930-2003. J. Geophys. Res. 110 (D22), 104. http://dx.doi.org/10.1029/2005JD 006181

Zhang, X., L. Alexander, G. C. Hegerl, P. Jones, A. K. Tank, T. C. Peterson, B. Trewin, and F. W. Zwiers, 2011: Indices for monitoring changes in extremes based on daily temperature and precipitation data, Wiley Interdiscip. Rev. Clim. Change, 2, 851-870.

https://doi.org/10.1002/wcc.147 